the participants' minds with the EPS at the outset, and to let them hear what it is all about from someone whom they respect for other reasons. There may be other things one can do. But the message is to project effectively the image of the EPS where we have the most intimate contact with the consumer.

Let me emphasise that the concern of the delegates is simply to promote the health of the Society; whether the analysis given above is completely accurate or not is almost beside the point. The most important thing at this stage is to gather views and canvass opinion as widely as possible. You are therefore urged to make your contribution by writing to this journal, expressing your views on any aspect of the issues raised. We hope that as a result of this exercise, your delegates and the other Council members will be better informed and can take appropriate action. But by writing you will also be helping this journal to evolve into a vehicle for the interchange of views and for improving lines of communication within the Society.

\section{D.N. Stacey}

(Clarendon Laboratory, Oxford)

\title{
First Reactions of the Executive Committee
}

Twenty years on is a good time for looking back and a good time for looking forward. Whilst in the past, it seemed that mere survival was the maximum ambition EPS could hope for, the Society has matured to a state where we should be rethinking our practices and our institutions with a view to further growth in size and value. This initiative of the IOM delegates is warmly welcomed because it highlights the preoccupations of the Society as a whole - and not least the Executive Committee. Communication within a widely dispersed organisation is always difficult and magic solutions are not to hand. Nevertheless improvements can be made and should be vigorously pursued.

\section{Europhysics News}

Europhysics News has a pivotal role to play in communications within the Society. The suggestion to have a section reserved for Divisions which can contain scientific notes, information about programmes and the organization of future meetings, comments about past meetings, information about Divisional Board meetings etc. and a section reserved for IOM's which can contain any suggestion, complaints etc. any IOM wishes to make is already de jure as Divisional News and IOM letters have always had priority. It is not de facto because although over the years we have made a number of attempts to encourage the Divisions to use Europhysics News for transmitting news to their members, the success has been thin. Nevertheless we should go on trying. As far as the section for IOM's is concerned, we can only urge members to sit down at their keyboards (and not to worry about their English as the editor can take care of that).

In effect what we should like to do is to keep the high level contents of Europhysics News as at present but expand the journal to include also more short news and personal items as well as the different 'back-end' features of magazines generally. Also we should like to make it more attractive in appearance.
But this all costs money which we do not have. However, a sub-committee consisting of the Secretary. Prof. M. Jacob, the Vice-Secretary, Dr. L. Cohen and the Vice-Treasurer Prof. J.M. Gilles are looking again to see what might be done within our boundary conditions.

\section{EPS Conferences}

We all agree that divisional conferences are of great value scientifically and they provide an excellent opportunity for recruiting the active scientists to EPS in a straightforward way. We have tried a number of times to get new IOM's at conferences by distributing pamphlets and specimen publications. Success has always been very small. The proposal that at the opening and also at the closing session of an EPS organized conference the chairman of the meeting or an IOM who is familiar with EPS should make a small speech on EPS and its role in Europe is strongly supported. This should be followed by an invitation to sign up for IOM membership.

\section{Priority for Presenting Papers}

There is a simple explanation for the statement that priority is given to IOMs for presenting papers at certain conferences. It may not be widely known that in the American Physical Society for example, sponsorship by members is needed to present papers at a number of important conferences if authors are not members in their own right. The agreements that have been negotiated with the AIP and the two physical societies in Japan give IOMs the same rights regarding conference presentations as members of those societies in their own countries.

\section{Delegates of IOM's and Associate Mem-} bers to Council

It is true that the delegates of IOM's and Associate Members are usually not well informed about the topics which will be discussed at Council and have no means to hear and thus represent the opinions of their fellow members. I have to add that most delegates representing national societies are not better off. Only few of them come to Council Meetings with clear instructions. At present the President of EPS opens Council by giving a relatively lengthy report about the activities, plans and problems of EPS. In order to be able to give this "State of the Union Message" he receives beforehand short reports from the Chairmen of the Advisory Committees and Divisions. Whereas the reports of the Advisory Committees are completely integrated into the President's Report, the Chairmen of the Divisions can present their reports themselves afterwards. The President's Report is followed by a general discussion, which in general, is not very long. One reason is that many Council delegates are not well informed about the salient issues nor have they had any opportunity to discuss them with their colleagues.

We are considering therefore a new procedure whereby in January the President receives from the Chairmen of the Advisory Committees and the Divisions their reports from which he prepares the President's Report which will be sent in February to all National Societies, and all Associate Members and to the nine Delegates of IOM's. This way, all the delegates can prepare themselves for the Council Meeting which is prescribed for the second half of March. In order that the delegates of IOM's can get some input from their IOM colleagues it is also suggested that a version of the President's Report be published with Europhysics News in February, i.e. some weeks before the Council Meeting, for circulation to the IOM's.

Following this procedure, the Report of the President will, on the one hand, take up less time and, on the other hand, the discussion period will become longer in time, more lively and thus more productive. Furthermore, it allows the IOM's to take a more active role in running the Society. And this is what we want.

W.J. Merz (Zürich) 